\title{
Assentamentos rurais no município de Anastácio-MS: algumas considerações para entendimento dos aspectos socioeconômicos ${ }^{1}$
}

\author{
Rural settlements in the municipality of Anastácio-MS: some considerations for \\ understanding socioeconomic aspects
}

Asentamientos rurales en el municipio de Anastácio-MS: algunas consideraciones para entender los aspectos socioeconómicos

\author{
Daiane Santana Santos \\ Mestra em Geografia, UFMS/CPAq, Brasil. \\ daianesantanageo@gmail.com \\ Valter Guimarães \\ Professor Doutor, UFMS/CPAq, Brasil. \\ vgeovalter@gmail.com
}

\begin{abstract}
${ }^{1} \mathrm{O}$ presente artigo é derivado da dissertação de mestrado, desenvolvida no Programa de Pós-Graduação stricto sensu, da Universidade Federal de Mato Grosso do Sul-Campus de Aquidauana/MS, intitulada "SUBSÍDIOS PARA O ENTENDIMENTO DA QUESTÃO SOCIOECONÔMICA EM PROJETOS DE ASSENTAMENTOS RURAIS NO MUNICÍPIO DE ANASTÁCIOMS: REALIDADE VERSUS PERSPECTIVAS". Autoria de Daiane Santana Santos e orientação do professor Dr. Valter Guimarães, mesma instituição.

Agradecimentos à Coordenação de Aperfeiçoamento de Pessoal de Nível Superior (CAPES) pela bolsa concedida à autora, durante o período de realização do curso.
\end{abstract}




\title{
Revista Científica ANAP Brasil
}

\author{
ISSN 1984-3240 - Volume 13, número 29, 2020
}

\section{RESUMO}

A presente pesquisa teve como objetivo central, criar subsídios ao entendimento de algumas questões socioeconômicas dos assentamentos rurais provenientes da reforma agrária, Monjolinho e São Manoel, localizados no município de Anastácio-MS. Além da revisão bibliográfica, foi realizado trabalho a campo com uso de entrevistas por meio da aplicação de formulários em ambos os assentamentos, utilizando-se do critério de amostragem. No São Manoel foram realizadas 30 entrevistas e no Monjolinho 32, sendo que foi considerado apenas as famílias que lá residem desde a fase de sua implementação ou ainda, aquelas que por motivos de falecimentos dos pais, permanecem morando nos lotes. Os entrevistados de ambos assentamentos, relataram a respeito das dificuldades de comercialização, que eram bem maiores do que possuem atualmente. Com o decorrer dos anos, e sem a possibilidade de realizar procedimentos para a correção dos solos, as famílias foram criando outras estratégias para realizar a sua (re)produção, investindo no gado leiteiro e posteriormente, de corte, pois o solo correspondeu bem à introdução das pastagens plantadas. Aliado a estas atividades, as plantações ficaram em segundo plano passando a ser realizado para o consumo próprio da família. A principal atividade praticada pelos assentados de ambos os assentamentos, é a pecuária de corte destinada para comercialização, porém, a principal fonte de renda das famílias deriva de recursos de aposentadoria. As famílias que lá permanecem venceram os obstáculos que foram surgindo da maneira como melhor julgaram que fosse viável para garantir a (re)produção da família, criando assim, vínculos fortes de afetividade nesse território.

PALAVRAS-CHAVE: Aspetos Socioeconômicos. Assentamentos Rurais. Reforma Agrária.

\section{ABSTRACT}

The main objective of this research was to create subsidies to the understanding of some socioeconomic issues of the rural settlements from the agrarian reform, Monjolinho and São Manoel, located in the municipality of Anastácio-MS. In addition to the literature review, field work was performed using interviews by applying forms in both settlements, using the sampling criterion. In São Manoel, 30 interviews were conducted and in Monjolinho 32, considering only the families who live there since the implementation phase or, still, those who for reasons of parents' deaths, remain living in the lots. The interviewees from both settlements reported the difficulties of marketing, which were much greater than they currently have. Over the years, and without the possibility of performing procedures for soil correction, the families were creating other strategies to carry out their (re)production, investing in dairy cattle and later, cut, because the soil corresponded well to the introduction of the planted pastures. Allied to these activities, the plantations were in the background of being carried out for the family's own consumption. The main activity practiced by the settlers of both settlements, is the cut livestock intended for commercialization, however, the main source of income of families derives from retirement resources. The families that remain there have overcome the obstacles that have arisen in the way they best thought was feasible to guarantee the (re)production of the family, thus creating strong bonds of affection in this territory.

KEY WORDS: Socioeconomic Aspects. Rural Settlements. Agrarian Reform.

\section{RESUMEN}

La presente investigación tuvo como objetivo central, crear subsidios al entendimiento de algunas cuestiones socioeconómicas de los asentamientos rurales provenientes de la reforma agraria, Monjolinho y São Manoel, ubicados en el municipio de Anastácio-MS. Además de la revisión bibliográfica, fue realizado trabajo en campo con uso de entrevistas por medio de la aplicación de formularios en ambos asentamientos, utilizándose del criterio de muestreo. En São Manoel se realizaron 30 entrevistas y en Monjolinho 32, siendo que fue considerado sólo las familias que residen allí desde la fase de su implementación o aún, aquellas que por motivos de fallecimientos de los padres, permanecen viviendo en los lotes. Los entrevistados de ambos asentamientos, relataron con respecto a las dificultades de comercialización, que eran mucho mayores de lo que poseen actualmente. Con el transcurso de los años, y sin la posibilidad de realizar procedimientos para la corrección de los suelos, las familias fueron creando otras estrategias para realizar su (re)producción, invirtiendo en el ganado lechero y posteriormente, de corte, pues el suelo correspondía bien a la introducción de los pastos plantados. Aliado a estas actividades, las plantaciones quedaron en segundo plano pasando a ser realizado para el consumo propio de la familia. La principal actividad practicada por los asentamientos de ambos, es la ganadería de corte destinada para comercialización, pero la principal fuente de ingresos de las familias deriva de recursos de jubilación. Las familias que allí permanecen vencieron los obstáculos que fueron surgiendo de la manera como mejor pensaron que sería viable para garantizar la (re)producción de la familia, creando así, vínculos fuertes de afectividad en ese territorio.

Palabras clave: Aspectos Socioeconómicos. Asentamientos Rurales. Reforma de la Tierra. 


\title{
Revista Científica ANAP Brasil
}

\author{
ISSN 1984-3240 - Volume 13, número 29, 2020
}

\section{INTRODUÇÃO}

Pesquisar a respeito de temáticas que envolvem projetos de assentamentos rurais, tem se tornado cada vez mais comum no cotidiano acadêmico. Em Mitidiero Junior (2011), ressalta-se a importância em estudar projetos de assentamentos de reforma agrária, pois, como aponta o autor, estes estudos em escala nacional ainda são bem recentes. Nesse sentido a pesquisa destinou-se a estudar dois projetos de assentamentos rurais: Monjolinho e São Manoel, ambos localizados no município de Anastácio - MS, no que concerne ao entendimento de questões de ordem socioeconômica das famílias assentadas. Para tal, realizou-se além do levantamento bibliográfico, o trabalho a campo, com aplicação de formulário em cada assentamento, utilizando-se método de amostragem.

A materialização de ambos os assentamentos foi marcada por muitos percalços, exigindo daqueles que estavam dispostos a conquistar o seu tão sonhado "pedaço de terra" uma luta constante, seja ela no momento da busca por esse direito, seja no momento em que nos lotes adentraram, pois, nessa nova etapa também necessitam batalhar para terem outros direitos que poderão ser determinantes para sua reprodução nesse novo espaço. Sendo assim, no decorrer desse processo de luta pela terra, as famílias enfrentaram acampamentos, realizaram ocupações e sofreram despejos, porém não desistiram do objetivo, que foi a conquista da terra.

\section{OBJETIVOS}

A presente pesquisa teve como objetivo geral, criar alguns indicadores para o entendimento da questão socioeconômica de famílias assentadas, no município de Anastácio-MS.

\section{MATERIAIS E METÓDOS}

\subsection{Coleta de dados no Assentamento Monjolinho}

Do total de 285 famílias que foram assentadas pelo INCRA ou ainda "do tempo da luta", estima-se que destas, aproximadamente 72 permanecem com os lotes, ou seja, restam $25 \%$ em relação ao número inicial de famílias assentadas. Porém, não significa dizer que destas 72 famílias todas lá residem, pois há casos em que a família assentada reside na cidade, além do fato de falecimento dos pais, mas os filhos lá permanecem ou não comercializaram a posse do lote. Assim, foram entrevistadas 32 famílias de assentados, levando-se em consideração apenas aquelas que permanecem no assentamento desde a fase de sua implementação, ou ainda, como os assentados costumam dizer "do tempo da luta".

\subsubsection{Coleta de dados no Assentamento São Manoel}

Do total de 147 famílias que foram assentadas pelo INCRA ou ainda "do tempo da luta", estima-se que destas, aproximadamente 59 permanecem com os lotes, ou seja, restam $40 \%$ em relação ao número inicial de famílias assentadas. Por outro lado, não significa dizer que destas 57 famílias todas lá residem, pois há casos em que a família assentada reside na cidade, além do fato de falecimento dos pais, mas os filhos lá permanecem ou não comercializaram a posse do lote. Desta forma, foram entrevistadas 30 (trinta) famílias, também, levando-se em consideração, apenas aquelas que do "tempo da luta". Após a coleta de dados, deu-se início a tabulação dos dados.

\section{BREVE HISTÓRICO DOS ASSENTAMENTOS}

\subsection{Assentamento Monjolinho}




\title{
Revista Científica ANAP Brasil
}

\author{
ISSN 1984-3240 - Volume 13, número 29, 2020
}

O Projeto de Assentamento Monjolinho com 9.525,2207 hectares foi implementado pelo Instituto Nacional de Colonização e Reforma Agrária (INCRA), tendo como ato de criação a Portaria № 01613 de 02/12/1988 e a forma de obtenção da área por compra e desapropriação datada de 18/11/1988, com capacidade para assentar 285 famílias, número este que foi totalmente preenchido².

Segundo Santos (2008) a área a qual pertence o Assentamento Monjolinho era de propriedade da Rede Ferroviária Federal S/A, e era utilizada para a retirada de madeira usada na confecção de dormentes a serem utilizados na via férrea e também para produção de carvão vegetal. Essa situação também foi relatada pelo entrevistado no 24 do Monjolinho durante a aplicação do formulário, na qual mencionou que: "tinha uma serraria lá onde agora é a sede do assentamento. Preparava os dormentes e levavam pra Aquidauana, por aquelas bandas" (Informação verbal) ${ }^{3}$.

Quanto à origem das famílias que permanecem assentadas, estas são provenientes de diversos municípios do Estado de Mato Grosso do Sul, conforme constato por meio do trabalho a campo, realizado por Santos (2019). Assim, 72\% relataram ter participado da ocupação da Gleba Santa Idalina, município de Ivinhema/MS, seja por eles próprios ou por seus pais, como foi o caso de 2 entrevistados que não participaram ativamente dessa ocupação mas que posteriormente a ela, permaneceram junto aos pais durante todas as outras fases de luta pela terra até o momento de conseguirem os lotes, permanecendo até os dias atuais mesmo com o falecimento dos pais. Por outro lado, houve também aqueles (22\%) que não participaram dessa ocupação da Gleba Santa Idalina em Ivinhema/MS pelo fato de pertencerem a outros grupos de sem-terra derivados de vários municípios do Estado de Mato Grosso do Sul, e foram transferidos para um assentamento provisório denominado Gleba Santo Inácio, à época (junho de 1987) ainda território de Anastácio, já que o município de Dois Irmãos do Buriti ainda não havia sido criado. Por fim, os demais, $6 \%$ disseram não ter participado desses dois acontecimentos, pois eram filiados ao Sindicato dos Trabalhadores Rurais de Anastácio, participando apenas da etapa do acampamento às margens do córrego Engano ${ }^{4}$ até que fosse realizado o sorteio dos lotes.

\subsubsection{Assentamento São Manoel}

O Projeto de Assentamento São Manoel com 4.321,0281 hectares também foi implementado pelo Instituto Nacional de Colonização e Reforma Agrária (INCRA), tendo como ato de criação a Resolução № 028 de 27/02/1992 e a forma de obtenção da área por compra e venda, datada de 24/01/1992, com capacidade para assentar 148 famílias, porém, 147 famílias foram assentadas ${ }^{5}$.

\footnotetext{
2 Projetos de Reforma Ágrária Conforme Fases de Implementação. Informação disponível em: $<$ http://www.incra.gov.br/sites/default/files/uploads/reformaagraria/questaoagraria/reformaagraria/projetos_criados-geral.pdf>. Acesso em 18 março de 2019. Em 2020, site com informações atualizadas, disponível no mesmo link, acessado em 6 fevereiro 2020. Para fins de confirmação da forma de obtenção da área do referido assentamento, buscou-se informação no E-Sic (Sistema Eletrônico do Serviço de Informação ao Cidadão). A informação foi respondida, via sistema eletrônico em 04/03/2020.

3 Informação adquirida durante aplicação de formulário com assentado de no 24 do Monjolinho em abril 2019.

${ }^{4}$ Que é uma divisa natural da área do assentamento com a fazenda denominada Água Boa.

5 Informação disponível em: Projetos de Reforma Ágrária Conforme Fases de Implementação <http://www.incra.gov.br/sites/default/files/uploads/reforma-agraria/questaoagraria/reformaagraria/projetos_criados-geral.pdf>. Acesso em 18 março de 2019. Em 2020, site com informações atualizadas, disponível no mesmo link, acessado em 6 fevereiro 2020. Para fins de confirmação da forma de obtenção da área do referido assentamento, buscou-se informação no E-Sic (Sistema Eletrônico do Serviço de Informação ao Cidadão). A informação foi respondida, via sistema eletrônico em 04/03/2020.
} 


\title{
Revista Científica ANAP Brasil
}

\author{
ISSN 1984-3240 - Volume 13, número 29, 2020
}

A área a qual pertence o assentamento São Manoel também era de propriedade da Rede Ferroviária Federal/S.A, e era utilizada para exploração de madeira para utilização na confeç̧ão de dormentes utilizados em suas linhas férreas (Silva e Almeida, 2002) e para uso em suas locomotivas a vapor (Silva, 2011). Destaca-se que, na aplicação dos formulários, houve também relatos de assentados que fizeram menção da área do assentamento anteriormente pertencer a "Rede" (se referindo a R.F.F/S.A) e outros simplesmente "Rede Ferroviária", e também, se recordaram da exploração de madeira que já estava sendo realizada no local, além da presença de carvoarias.

Quanto à origem das famílias que permanecem assentadas, estas são provenientes de diversos municípios do Estado de Mato Grosso do Sul, conforme constato por meio do trabalho a campo, realizado por Santos (2019). Assim, Do total de entrevistados, 44\% relataram ter participado da ocupação da Gleba Santa Idalina, seja por eles próprios ou por seus pais, como foi o caso de 2 de entrevistados, porém, posteriormente à esta ocupação, lutaram ativamente junto aos pais. Houve também aqueles (27\%) que não participaram dessa ocupação (Gleba Santa Idalina), pois, relataram que moravam em Dois Irmãos do Buriti/MS, e trabalhavam em fazendas, tanto como funcionários, ou arrendatários. Por fim, 7\% mencionaram que, moravam no assentamento Guaicurus, município de Bonito/MS, porém, em terras de terceiros; $13 \%$ moravam no assentamento Nioaque (antiga Fazenda Conceição), município de Nioaque/MS, como agregados (moravam e trabalhavam no lote de seus pais)73; 3\% trabalhava em uma fazenda no município de Campo Grande/MS; 3\%, também, morou em fazenda, no município de Anastácio/MS, bem próximo à área do assentamento São Manoel, e, finalmente, $3 \%$ saiu do processo de luta pela terra do assentamento vizinho (Monjolinho), quando a referida área (Fazenda Monjolinho), ainda estava em tramitação para de fato, formar-se em assentamento.

Figura 1- Mapa de localização das áreas pesquisadas-município de Anastácio/MS.

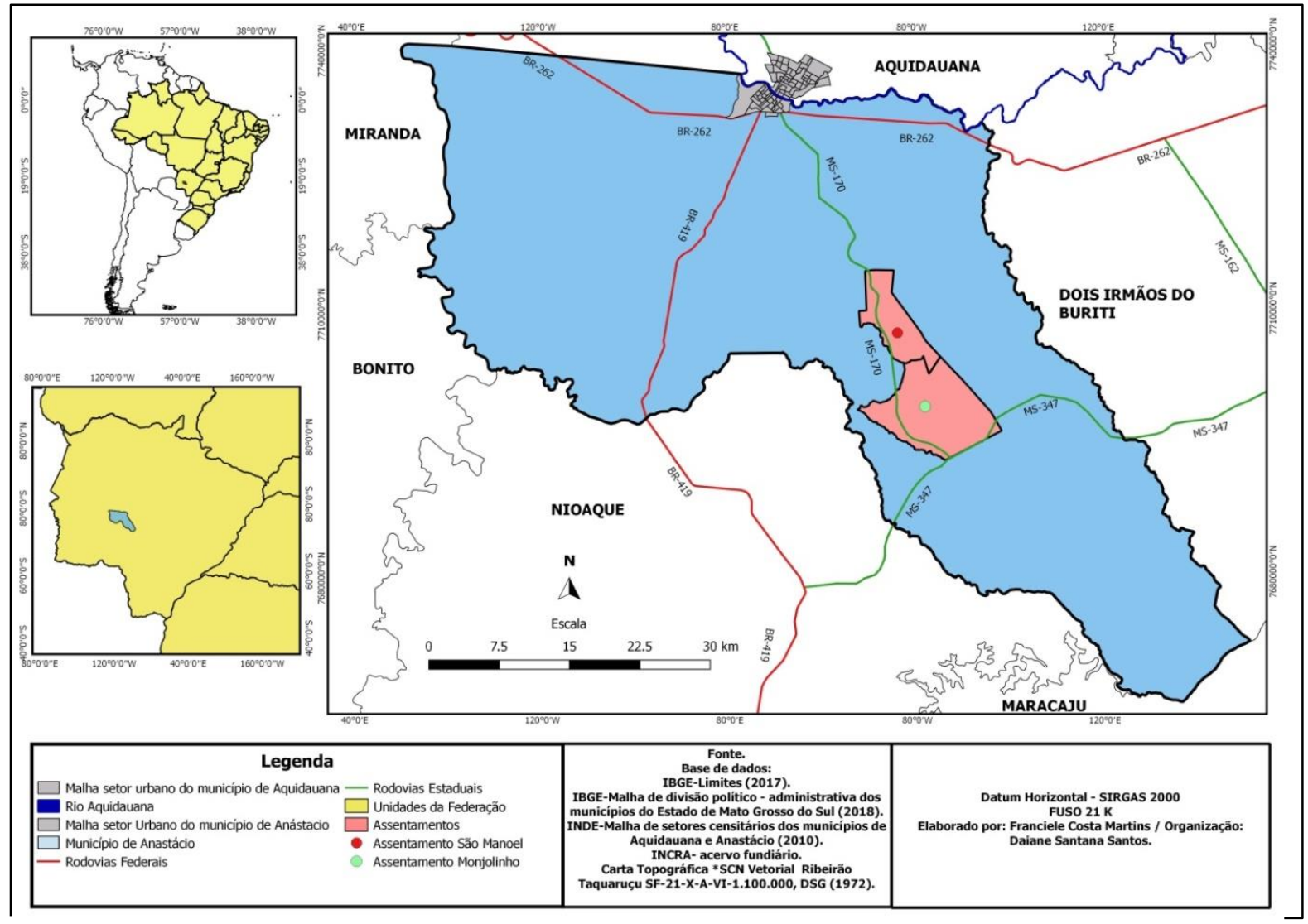

Fonte: Elaborado por Franciele Martins e organizado por Daiane Santana Santos. 
Revista Científica ANAP Brasil

ISSN 1984-3240 - Volume 13, número 29, 2020

\section{RESULTADOS I (Assentamento MONJOLINHO)}

Figura 2- Estrutura fundiária do Assentamento Monjolinho e espacialização dos lotes abarcados na pesquisa.

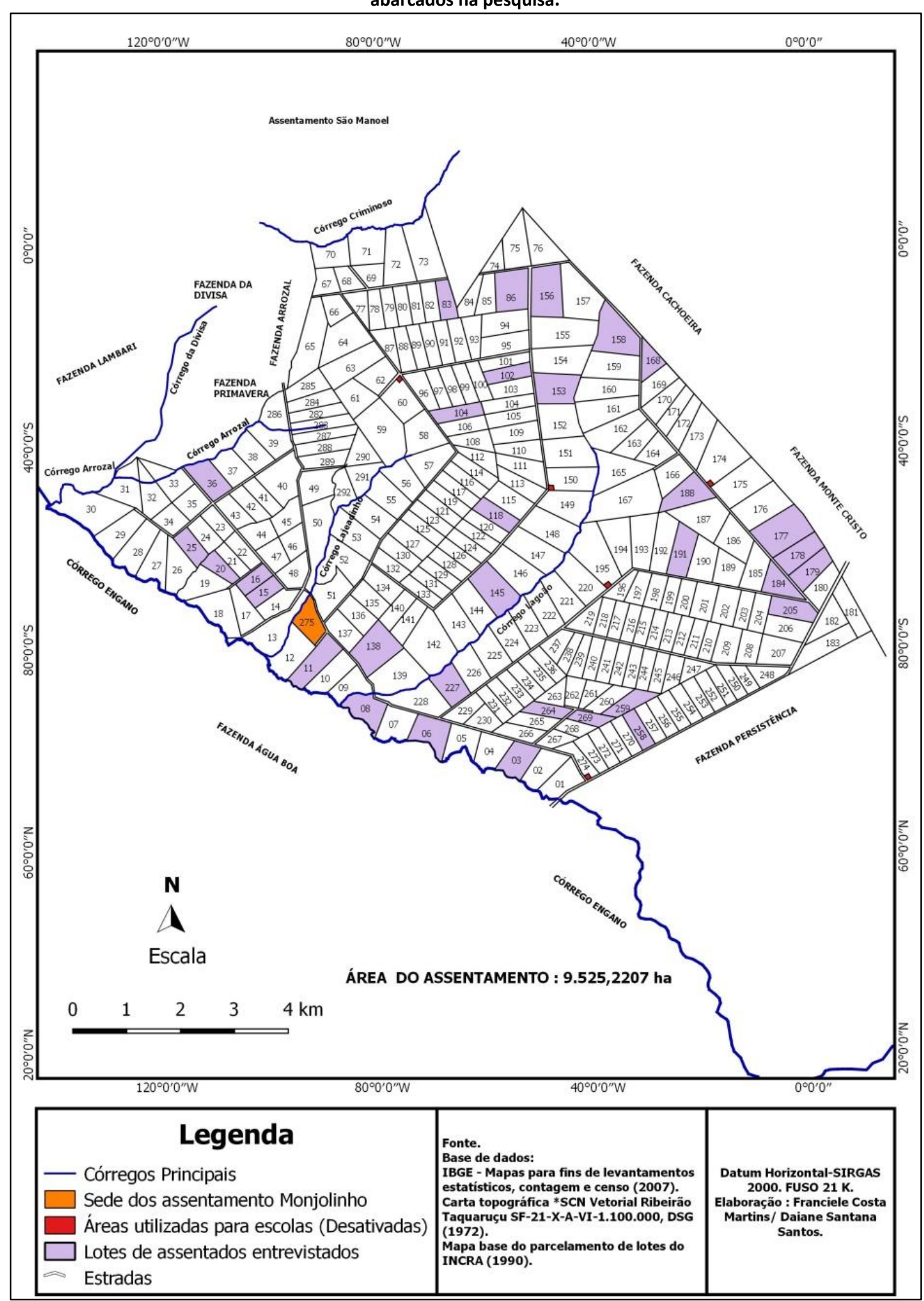

Fonte: Elaborado por Franciele Costa Martins e organizado por Daiane Santana Santos (2019).

\subsection{Dimensões dos lotes abarcados na pesquisa}




\title{
Revista Científica ANAP Brasil
}

\author{
ISSN 1984-3240 - Volume 13, número 29, 2020
}

As dimensões dos lotes no assentamento são bastante variáveis, isto devido às condições de cada ambiente onde os lotes estão inseridos. Desta forma, segundo o próprio INCRA:

\begin{abstract}
A quantidade de glebas num assentamento depende da capacidade da terra de comportar e sustentar as famílias assentadas (continua na próxima página).

O tamanho e a localização de cada lote é determinado pela geografia do terreno e pelas condições produtivas que o local oferece "[...] (INCRA, 2020 COMO É UM ASSENTAMENTO) ${ }^{6}$.
\end{abstract}

Quadro 1- Assentamento Monjolinho: dimensão dos lotes abarcados na pesquisa.

\begin{tabular}{|c|c|c|}
\hline Intervalos de dimensões & $\begin{array}{c}\text { Somatório das } \\
\text { respostas obtidas }\end{array}$ & Valores em porcentagem \\
\hline De $18-30$ hectares & 14 & $44 \%$ \\
\hline De $31-40$ hectares & 8 & $25 \%$ \\
\hline Acima de 40 hectares & 10 & $31 \%$ \\
\hline Total & 32 & $100 \%$ \\
\hline
\end{tabular}

Fonte: pesquisa a campo (2019).

\subsubsection{Atividades praticadas atualmente pelos entrevistados}

Por meio da pesquisa a campo (Santos, 2019), foi possível compreender que, a primeira cultura que os entrevistados realizaram, quando adentraram aos lotes, foi o cultivo do algodão, dos quais $91 \%$ relataram ter cultivado $16 \%$ que chegaram a cultivar, mas não obtiveram êxito e $9 \%$, não realizaram. Aliado ao cultivo do algodão, todos os entrevistados relataram que também desenvolviam outros cultivares como mandioca, milho, feijão, arroz, banana, nas chamadas roças, nas quais mencionaram que plantavam "de tudo um pouquinho". A produção de leite também já foi atividade destaque no assentamento, porém, foi perdendo espaço com o decorrer dos anos. Também foi relatado a respeito das dificuldades de comercialização, bem maiores do que atualmente, além, dos valores irrisórios pagos pelos compradores.

Ao questionar a respeito de qual atividade predomina no lote, obteve-se as seguintes respostas, ilustradas a seguir.

\footnotetext{
${ }^{6}$ Informação disponível em <http://www.incra.gov.br/assentamentos_caracteristicas>. Acesso em 30 maio 2019. Em 2020 o site foi atualizado e a referida informação se encontra no link: <http://www.incra.gov.br/pt/assentamentos.html.>.Acesso em 6 fev. 2020.
} 


\section{Revista Científica ANAP Brasil}

ISSN 1984-3240 - Volume 13, número 29, 2020

Figura 3- Assentamento Monjolinho: Atividades predominantes praticadas pelos assentados entrevistados.

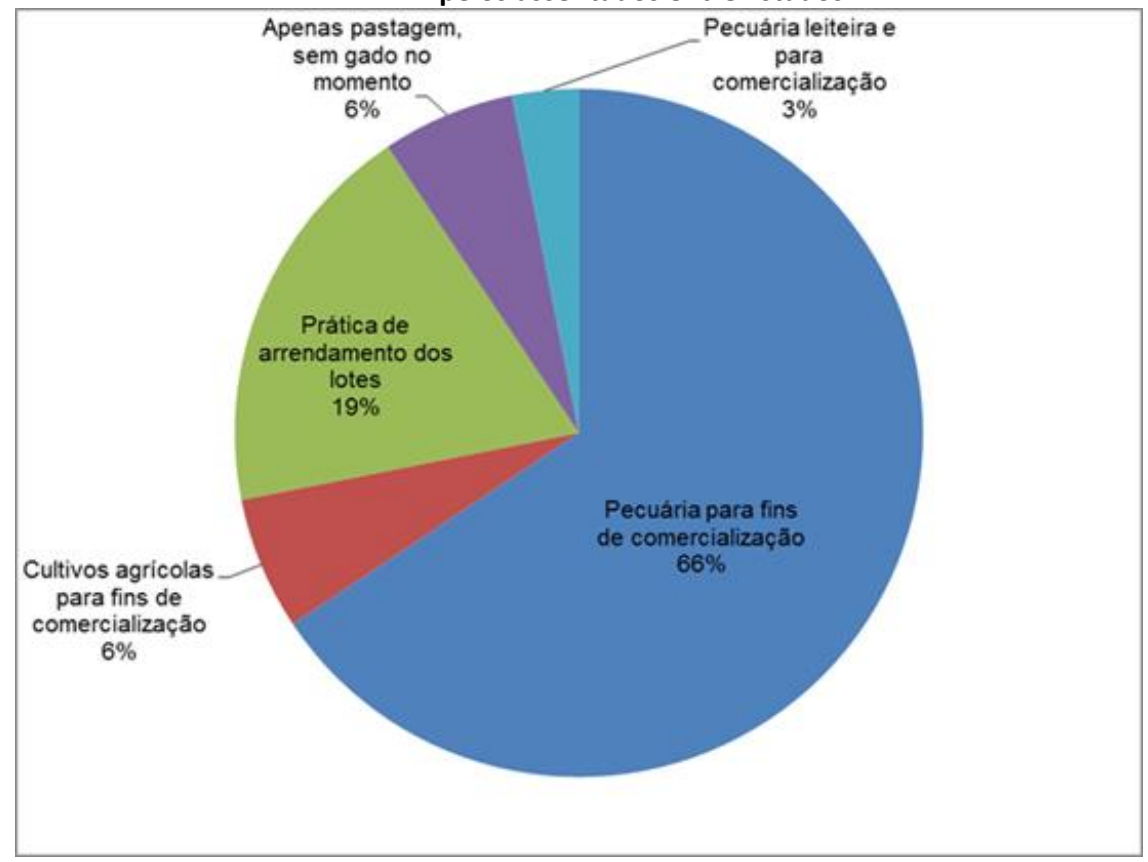

Fonte: pesquisa a campo (2019).

Nota-se a partir da representação do gráfico acima que a prática da pecuária para fins de comercialização $(66 \%)$ é a atividade predominante nos lotes. Porém, cabe ressaltar que esta prática é realizada, em sua maior parte, pela venda do bezerro, quando estes atingem certa idade, ou ainda, quando há necessidade de obter algum recurso financeiro mais rápido.

Do total de entrevistados, 25 consideram a qualidade do solo que possuem em seu lote como sendo ruim, $59 \%$ consideram regular e por fim, 16\% consideram como boa. Porém, para se tornar um solo regular, foi relato que há a necessidade de realizar melhorias nesse solo. 


\title{
Revista Científica ANAP Brasil
}

\author{
ISSN 1984-3240 - Volume 13, número 29, 2020
}

\subsubsection{Origem da Renda Familiar dos Entrevistados}

Coube ainda indagar a respeito de qual origem provém a renda familiar dos entrevistados. Os resultados obtidos demonstram que $85 \%$ têm como fonte de renda mensal recursos provenientes de aposentadoria, seguido de $9 \%$ que também recebem aposentadoria, porém, complementam a renda comercializando produtos na Feira da Agricultura Familiar, realizada na sede do município de Anastácio-MS. Há também, a Associação de Mulheres Agricultoras do Assentamento Monjolinho (AMAM), na qual as integrantes ativas (corresponde a duas mulheres que foram abarcadas na pesquisa) já estão conseguindo obter algum lucro com a venda de seus produtos, mesmo não sendo um valor fixo todos os meses.

Figura 4- Assentamento Monjolinho: Origem da renda familiar dos entrevistados.

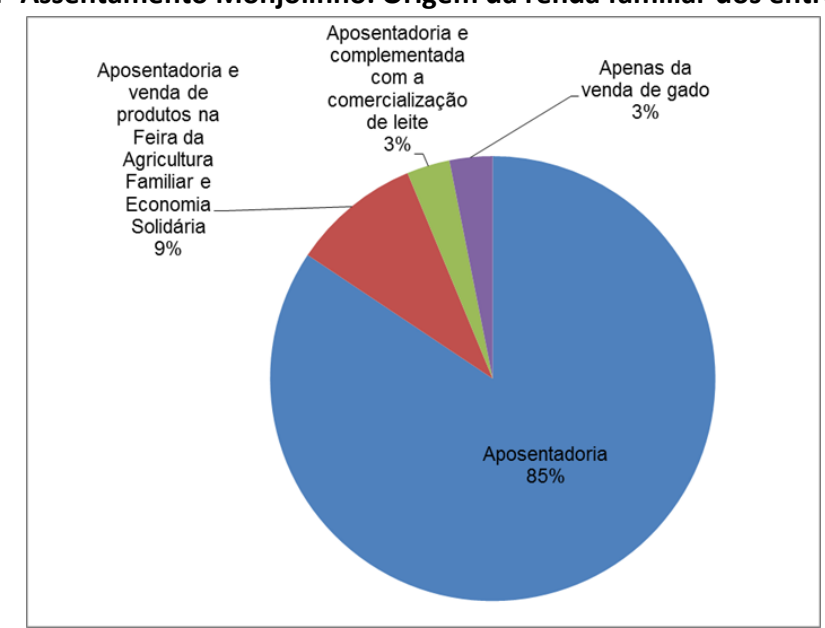

Fonte: pesquisa a campo (2019).

Essa situação da renda familiar chama atenção, pois esta se contrapõe com a situação averiguada das principais atividades desenvolvidas pelos entrevistados, na qual predomina a prática da pecuária para comercialização.

\subsubsection{Questões relacionadas à permanência na terra}

Decorridos oficialmente os 30 anos de existência do assentamento, considerou-se pertinente, realizar questionamentos a respeito da permanência na terra pelos entrevistados.

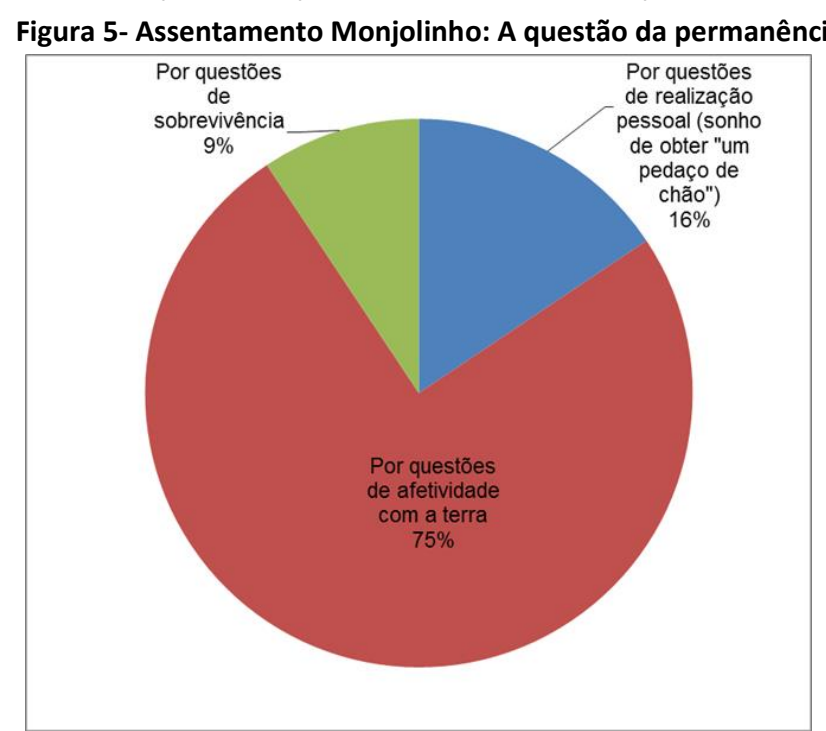

Fonte: pesquisa a campo (2019). 


\section{Revista Científica ANAP Brasil}

\section{ISSN 1984-3240 - Volume 13, número 29, 2020}

Quando questionados a respeito das perspectivas em relação ao "seu" lote, $84 \%$ relataram que pretendem continuar morando no lote enquanto houver condições de realizar suas atividades e $16 \%$ pretendem continuar morando ao menos pelos próximos dez anos.

\section{RESULTADOS II (ASSENTAMENTO SÃO MANOEL)}

Figura 6- Estrutura fundiária do Assentamento São Manoel e espacialização dos lotes abarcados na pesquisa.

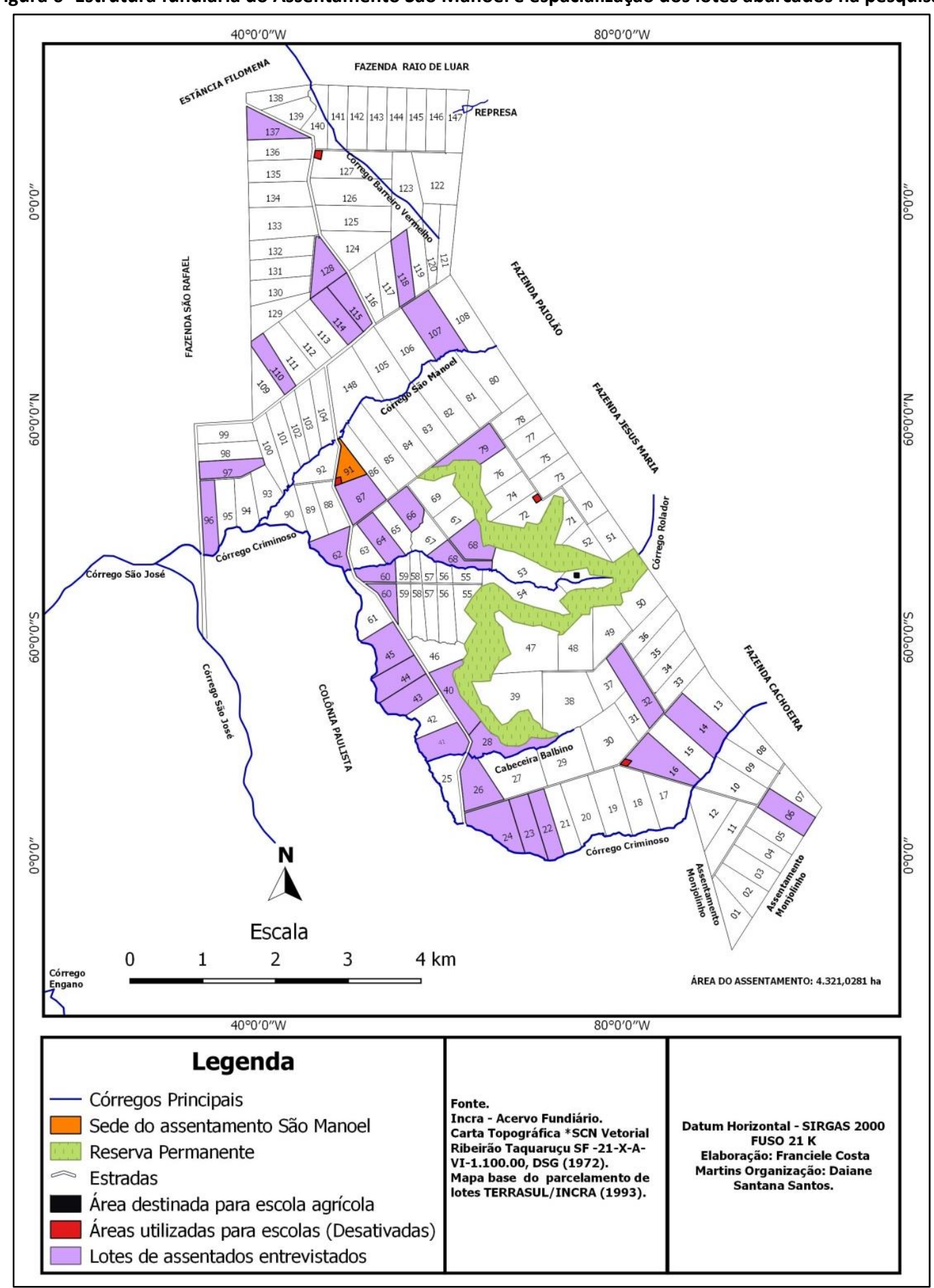

Fonte: Elaborado por Franciele Costa Martins e organizado por Daiane Santana Santos (2019). 


\title{
Revista Científica ANAP Brasil
}

\author{
ISSN 1984-3240 - Volume 13, número 29, 2020
}

Assim, como no Assentamento Monjolinho, no Assentamento São Manoel as dimensões dos lotes também apresentam-se variadas, conforme ilustradas no quadro a seguir.

Quadro 2- Assentamento São Manoel: dimensão dos lotes abarcados na pesquisa.

\begin{tabular}{|c|c|c|}
\hline $\begin{array}{c}\text { Intervalos de } \\
\text { dimensões }\end{array}$ & $\begin{array}{c}\text { Somatório das respostas } \\
\text { obtidas }\end{array}$ & $\begin{array}{c}\text { Valores em } \\
\text { porcentagem }\end{array}$ \\
\hline De 19-30 hectares & 23 & $77 \%$ \\
\hline De 31- 40 hectares & 6 & $20 \%$ \\
\hline $\begin{array}{c}\text { Acima de } 40 \\
\text { hectares }\end{array}$ & 1 & $3 \%$ \\
\hline Total & 30 & $100 \%$ \\
\hline
\end{tabular}

pesquisa a campo (2019).

\subsection{Atividades praticadas atualmente pelos entrevistados}

Os entrevistados relataram que desde o tempo em que estavam na área do assentamento, aguardando para a divisão dos lotes, já desenvolviam as "roças". Assim, quando adentraram nos lotes realizavam diversas plantações, como abóbora, algodão, arroz, banana, feijão, mandioca, melancia, milho. Aqueles que participaram da Cooperativa que se formou logo no início do assentamento e durou cerca de dez anos (ocorreu com 3 entrevistados), também realizaram plantações diversas, como algodão, banana, feijão, tomate e verduras. Nas duas situações (produção individual e coletiva, na cooperativa) foram relatadas dificuldades de comercialização dos produtos, havendo casos de vendas para atravessadores e ainda, mencionado a expressão no sentido de dizer que "naquele tempo, as coisas eram mais difíceis". A produção de leite também já foi outra atividade de destaque, mas também veio perdendo espaço, com o passar dos anos. A seguir, ilustração das principais atividades desenvolvidas pelos entrevistados.

Figura 7- Assentamento São Manoel: Atividades predominantes praticadas pelos entrevistados.

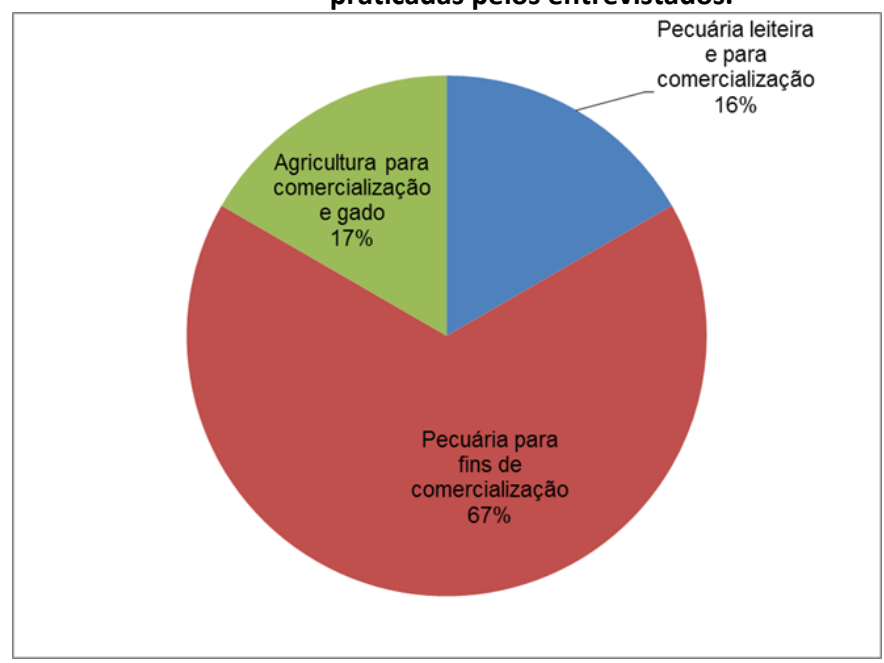

Fonte: pesquisa a campo (2019).

Nota-se que, a prática da pecuária para fins de comercialização é a atividade predominante nos lotes, porém, os assentados realizam a comercialização de gado, (na maioria, os bezerros) quando esses atingem a idade ideal, ou ainda, quando há necessidade de obter algum recurso financeiro mais rápido. Apesar da fonte de renda da maioria ser derivada de recursos de 


\title{
Revista Científica ANAP Brasil
}

\author{
ISSN 1984-3240 - Volume 13, número 29, 2020
}

aposentadoria, esta é complementada com a venda de leite (um caso) e venda de produtos derivados da produção no Grupo Baru (Grupo de Mulheres do Assentamento) e também, de verduras, na Feira da Agricultura Familiar de Anastácio/MS. As vendas para Programas como Programa de Aquisição de Alimentos (PAA) e Programa Nacional de Alimentação Escolar (PNAE), citados por pessoas que são aposentadas, são realizadas quando estas possuem determinados produtos. Já os que possuem como fonte de renda, a venda de plantação e serviços externos nos lotes se dá em decorrência de exercer atividade em órgão público (um caso) exercer atividade política na Câmara Municipal de Anastácio/MS (um caso) e, por fim, um caso que realiza plantações e outros serviços externo ao lote. Aqueles que vendem leite e exercem atividade fora do lote, se deu pelo fato de exercer atividade pública.

Cabe destaque, os $17 \%$ dos entrevistados em que a prática da agricultura foi mencionada como a principal opção de atividade, pois é esta a quem eles se dedicam cotidianamente, ou seja, também possuem sua criação de gado, porém o foco não está na criação.

Do total de entrevistados, $10 \%$ consideram a qualidade do solo que possuem em seu lote como sendo ruim, $23 \%$ consideram regular, e, por fim, $67 \%$ consideram como boa. Porém, também foi relato que, para se tornar um solo regular, foi relato que há a necessidade de realizar melhorias nesse solo.

\subsubsection{Origem da Renda Familiar dos Entrevistados}

Coube indagar a respeito a respeito da origem da renda familiar entrevistados, obtendo-se os dados a seguir.

Figura 8- Assentamento São Manoel: Origem da renda familiar dos entrevistados.

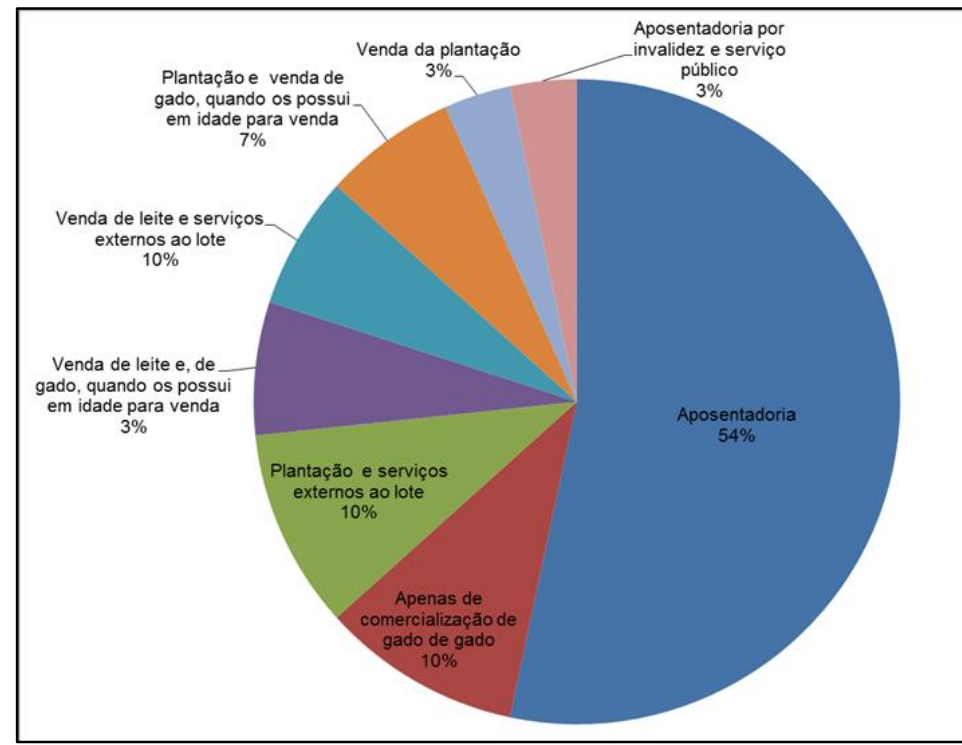

Fonte: pesquisa a campo (2019).

Nota-se que prevalece a renda mensal derivada de recursos provenientes de aposentadoria. Esta situação da renda familiar chama atenção, pois mesmo a atividade principal sendo a pecuária, apenas $10 \%$ mencionou que vivem exclusivamente dela. 


\section{Revista Científica ANAP Brasil}

ISSN 1984-3240 - Volume 13, número 29, 2020

\subsubsection{Questões relacionadas à permanência na terra}

Decorridos oficialmente 26 anos de existência do assentamento, considerou-se pertinente, realizar questionamentos a respeito da permanência na terra pelos entrevistados, obtendo-se as seguintes respostas.

Figura 9- Assentamento São Manoel: A questão da permanência na terra.

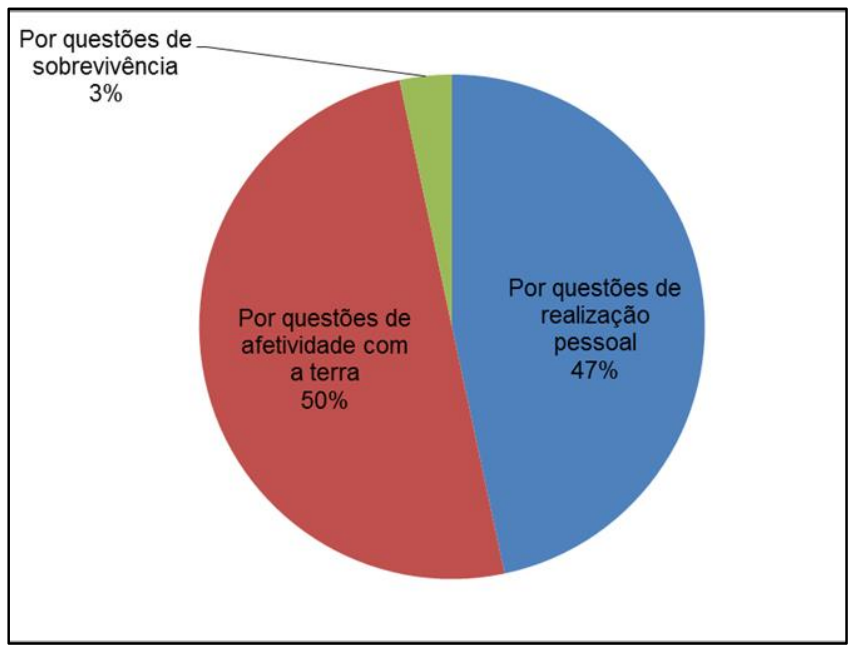

Fonte: pesquisa a campo (2019).

Quando questionados a respeito das perspectivas que os assentados possuem em relação ao "seu lote", 67\% relataram que pretendem continuar morando no lote enquanto houver condições de desenvolver suas atividades, $20 \%$ pretendem continuar morando no lote ao menos pelos próximos dez anos, porém, destacaram que gostam do lugar onde vivem, e por fim, 13\% disse que nunca pensou em vender o lote. No geral, muitos relataram questões no sentido de dizer que "dos que venderam os lotes, estes, atualmente, não se encontram em boas condições de vida".

\section{CONCLUSÃO}

As áreas dos assentamentos Monjolinho e São Manoel pertenciam a uma empresa estatal do governo federal. Depois de adquiridas as respectivas áreas, tendo como forma de obtenção o ato de "compra e venda", para serem destinadas à reforma agrária, mediante reivindicação de famílias sem terra, mudou-se apenas o caráter de posse já que estas mesmas áreas continuam a ser de domínio da União, pois as famílias ainda não possuem a escritura dos lotes. Mesmo assim, as referidas áreas passaram a se constituir no território dos assentamentos, pois aqueles que nelas estão realizaram a sua territorialidade, ou seja, sua re(produção) social.

Os entrevistados de ambos assentamentos, relataram a respeito das dificuldades de comercialização, que eram bem maiores do que possuem atualmente. Com o decorrer dos anos, e sem a possibilidade de realizar procedimentos para a correção dos solos, as famílias foram criando outras estratégias para realizar a sua (re)produção, investindo no gado leiteiro e posteriormente, de corte, pois o solo correspondeu bem à introdução das pastagens plantadas. Aliado a estas atividades, as plantações ficaram em segundo plano passando a ser realizado para o consumo próprio da família. 


\title{
Revista Científica ANAP Brasil
}

\author{
ISSN 1984-3240 - Volume 13, número 29, 2020
}

Como pôde ser constatado por meio do trabalho a campo, a principal atividade praticada pelos assentados de ambos os assentamentos, é a pecuária de corte destinada para comercialização, porém, a principal fonte de renda das famílias deriva de recursos de aposentadoria. Cabe exceção, um quantitativo de assentados do São Manoel (17\%) que consideraram a agricultura como sendo sua principal atividade desenvolvida no lote, seguida da pecuária para comercialização.

Portanto, diante de todo o processo de luta pela terra e na terra, as famílias que lá permanecem venceram os obstáculos que foram surgindo da maneira como melhor julgaram que fosse viável para garantir a (re)produção da família. Também, consideram estar atualmente "no paraíso" devido a tanto sofrimento que passaram ao longo de suas vidas, principalmente, quando da luta pela terra. Assim, sentem-se orgulhosos por tudo que conseguiram conquistar, mesmo sabendo não serem donos oficialmente do lote onde vivem. Com isso, passaram a ter o assentamento como o seu território de vida, atribuindo valores sentimentais profundos e não se veem morando em outro lugar que não seja em "seu" lote.

\section{REFERÊNCIAS BIBLIOGRÁFICAS}

INCRA- Instituto Nacional de Colonização e Reforma Agrária. Como é um assentamento. Disponível em: $<$ http://www.incra.gov.br/assentamentos_caracteristicas. Acesso em: 30 maio 2019. Em 2020, o site foi atualizado e essa informação se encontra no link: <http://www.incra.gov.br/pt/assentamentos.html?id=223>. Acessado em 11 fev.2020.

INCRA- Instituto Nacional de Colonização e Reforma Agrária. Projetos de Reforma Ágrária Conforme Fases de Implementação. Período da Criação do Projeto: 01/01/1900 Até 18/02/2020. Disponível em: <http://www.incra.gov.br/sites/default/files/uploads/reforma-agraria/questao-agraria/reformaagraria/projetos_criados-geral.pdf. Acesso em: 18 mar. 2019. Em 2020, site com informações atualizadas, mesmo link, acessado em 6 fev.2020.

MITIDIERO JUNIOR, Marco Antonio. Reforma agrária no Brasil: algumas considerações sobre a materialização dos assentamentos rurais. Revista Agrária, (São Paulo.online) n. 14, jun. 2011. Disponível em: <http://www.revistas.usp.br/agraria/article/view/55794/59203>. Acesso em: 22 maio 2015.

SANTOS, Daiane Santana. Subsídios para o entendimento da questão socioeconômica em projetos de assentamentos rurais no município de Anastácio-MS: realidade versus perspectivas. 2020. Dissertação (Mestrado em Geografia)-Universidade Federal de Mato Grosso do Sul, Campus de Aquidauana.

SANTOS, Édla Gonçalves Lopes dos. As relações de uso e ocupação com a aptidão agrícola das terras: assentamento Monjolinho-Anastácio/MS. 2008. Dissertação (Mestrado em Geografia) - Universidade Federal de Mato Grosso do Sul, Campus de Aquidauana.

SILVA, Jaime Ferreira da. Modelo de análise de assentamento rural: uma contribuição para gestão ambiental. 2011. Tese (Doutorado em Engenharia Civil) - Universidade Federal de Santa Catarina, Florianópolis.

SILVA, Tânia Paula da; ALMEIDA, Rosemeire Aparecida de. A experiência do trabalho coletivo e as transformações territoriais no assentamento São Manoel, em Anastácio/MS. Geografia(Londrina), Londrina, v. 11, n. 2, Jul/Dez, 2002. Disponível em: <http://www.uel.br/revistas/uel/index.php/geografia/article/view/6723/6065>. Acesso em 21 jan. 2019. 
Revista Científica ANAP Brasil

ISSN 1984-3240 - Volume 13, número 29, 2020

APÊNDICE A

Junção das áreas dos assentamentos pesquisados, com objetivo de demonstrar que, antes da ocorrência das desapropriações, estas áreas constituíam o território pertencente à Rede Ferroviária Federal S.A.

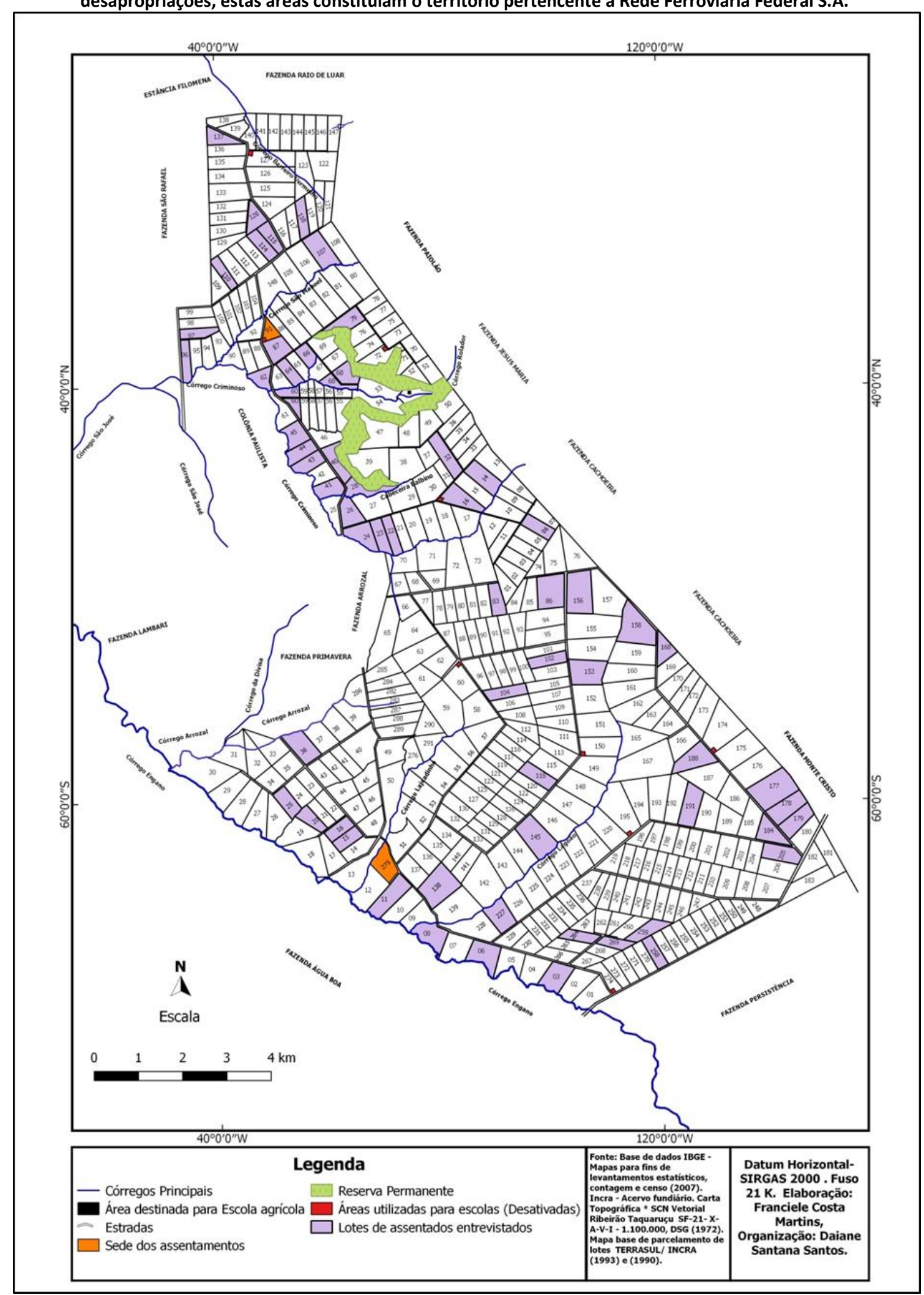

Fonte: Elaborado por Franciele costa Martins e organizado por Daiane Santana Santos (2019). 